\title{
L'ADMINISTRACIÓ DE LA COMANDA HOSPITALERA DE BARBERÀ: \\ UN LLIBRE DE COMPTES DE 1410-1411
}

GASPAR FELIU

Universitat de Barcelona

\begin{abstract}
SUMARI
1. El llibre de comptes.- 2. La comanda de Barberà com a explotació senyorial.- 3. L'any agrícola.- 4. Els jornals i altres despeses de treball.5. Les despeses d'explotació.- 6. La despesa de cuina i el menjar.- 7. Una aproximació al compte d'explotació.- 8. Apèndix I.- 9. Apèndix II.
\end{abstract}

Sabem molt poc de l'economia dels senyors feudals, Ordes Militars incloses, i encara menys pels temps medievals ${ }^{1}$. Per això $m$ 'ha semblat que l'estudi d'un petit volum de comptes de la comanda de Barberà corresponent als anys $1410-1411^{2}$ podia ser adient en aquest homenatge a Regina Sáinz de la Maza, amb qui tantes hores profitoses havíem compartit en l'Arxiu de la Corona d'Aragó i també al CSIC.

Aquest llibre de comptes permet examinar quatre aspectes diferents, però conectats: el funcionament de l'explotació senyorial, i per tant la renda senyorial real, el curs dels treballs durant l'any agrícola, els costums alimentaris i els preus i jornals de tots tipus. És però una visió geogràficament i cronològicament puntual i amb una mancança greu: abarca només

\footnotetext{
'Aquest treball ha estat realitzat dins del PSPGC del MEC, projecte PB96-0242, finançat per la DGES.

${ }^{2}$ ACA, Monacals. Hisenda, vol. 3762, "Libre de Rebudes e despeses que fan dins lo castell de Barberà axí de diners, de blats com de altres coses, lo qual libre fonch feyt per mi frare Bernad de Vilaregut regidor en lo dit loch de Barberà per monsenyor lo comenador de Guardeny lochtinent en lo Priorat de Catalunya per nostro senyor lo papa, lo qual libre fonch feyt ha XX IIII dies del mes de jun del any M CCCC e deu".
}

"Anuario de Estudios Medievales", 28 (1998) 
onze mesos, de manera que desconeixem les despeses que pogué comportar la sega, cosa que deixa coixos molts dels càlculs. Conté menys informació que els comptes semblants publicats fa anys per Altisent, peró és una mica més antic $\mathrm{i}$ en alguns aspectes els pot servir de complement ${ }^{3}$.

\section{EL LLIBRE DE COMPTES}

Es tracta d'un volum en foli, cosit, però sense enquadernar, de 52 fulls, amb una full de guarda posterior (l'anterior s'ha perdut) i un full solt al mig, de lletra diferent. Els comptes foren portats per fra Bernat de Vilaregut, que devia entrar de regidor per Sant Joan de 1410; no arribà a completar l'any, donat que les anotacions s'acaben el 22 de maig de 1411 . La lletra és gòtica cursiva bastant clara i no presenta dificultats de lectura. La tècnica comptable utilitzada és senzilla, de càrrec i data; tanmateix, fra Bernat no n'era gaire expert i els comptes no sempre són prou clars. De fet es tracta diversos comptes copiats l'un darrera l'altre, però sense cap balanç final. Els comptes són: despeses de blat per la casa, venda de cereals, despeses vàries (compres, jornals), compte dels jornals d'esporgar la vinya, separats del compte general de jornals, $\mathrm{i}$ compte de la despesa ordinària $\mathrm{i}$ extraordinària, o sigui del cost del producte principal del menjar diari. En un full solt insert al mig del llibre hi ha encara un compte de cereals, sens dubte posterior a l'administració de Vilaregut, donat que s'hi refereix, que ens permet conéixer que la comanda (o el comanador) disposaven també en aquest moment de terres o rendes a Comalats ${ }^{4}$; segurament es tracta de la comanda de Vallfogona, que a vegades consta com a independent $\mathrm{i}$ altres unida a Barberàs. Els cereals portats de Comalats eren una quantitat gairebé igual a l'obtinguda a Barberà.

\footnotetext{
${ }^{3}$ Agustí Altisent, Les granges de Poblet al segle XV. Assaig d'història agrària d'unes granges cistercenques catalanes. Barcelona, 1972.

${ }^{4}$ Comalats són les serres i altiplans que separen la Conca de Barberà de la Segarra.

${ }^{5}$ Paper solt insertat en el llibre de comptes, obra de fra Guillem Sancho, successor de fra Bernat de Vilaregut. Sobre la comanda de Vallfogona, MIRET, Les cases, pp. 346-347 i Josep $\mathrm{M}^{\mathrm{a}}$ SANS I TRAVÉ, La comanda del Temple de Vallfogona de Riucorb. Primera part: la creació i formació del patrimoni (segles XII $i$ XIII), "Quaderns d'Història Tarraconense", II (1980), p.
} 
Per regla general els càlculs són correctes, però es detecten algunes errades $\mathrm{i}$ bastantes omissions ${ }^{6}$. Podem afegir que fra Bernat patia d'una certa dislèxia: paraules com forn, carn y any, que es repeteixen sovint, apareixen sempre escrites "fron", "cran" y "ayn". En canvi té molta cura amb les mesures, indicant d'on són i les seves equivalències. Per desgràcia però, les mesures, tèoricament inmutables, es comporten com a éssers vius: les mesures que apareixen en els comptes no s'adiuen mai prou bé amb les que gairebé dos segles més tard foren codificades per ordre de les corts de Montsó, però tampoc les diferències no són gaire grans. A l'Apèndíx I discuteixo les mesures que apareixen en el document. Ara n'hi ha prou amb dir que considero que la mitgera utilitzada és la de Barberà o Montblanc, de 115,864 1. Pel que fa a la moneda, com passa també amb els comptes de Poblet ja citats ${ }^{7}$, es prescindeix de les lliures ${ }^{8}$ : totes les quantitats i tots els comptes s'expressen en sous i diners.

\section{LA COMANDA DE BARBERÀ COM A EXPLOTACIÓ SENYORIAL}

La comanda hospitalera de Barberà procedia del Temple i havia estat una de les primeres possessions templeres a Catalunya, per donació feta l'any 1132 pel comte Ermengol VI d'Urgell, el qual tenia el castell de Barberà en feu pel comte de Barcelona, que consentí i lloà la donacióp . Sembla que el 1410 la comanda de Barberà estava unida a la de Gardeny, prefigurant el que serien posteriorment les quatre "cambres priorals", o sigui les comandes les rendes de les quals estaven assignades al Gran Prior. El

\footnotetext{
${ }^{6}$ Com que per una banda comptabilitza els jornals pagats i per una altra el menjar, de vegades al compte de menjar surt com a llogat algú que no apareix en el compte de salaris.: Els dies en què consta pagat un salari i els que el treballador dinà al castell tampoc no concorden sempre, però això és menys important. També en alguns moments es descuida d'anotar les despeses de menjar durant un o més dies. De tota manera els errors són una part petita del conjunt $\mathrm{i}$ al meu entendre no invaliden la visió general; en tot cas fra Bernat no erá un administrador infidel, sinó descurat: els errors anaven gairebé sempre en contra seva.

${ }^{7}$ ALTISENT, Les granges.

${ }^{8}$ Només s'ementa una quantitat en lliures, les 9 lliures i mitja de la "coqueleria" del forn de Barberà, que devia ser citada així en el document, i precisament no es trasllada la quantitat a la columna de les sumes, com si l'administrador no sabés fer la transformació.

${ }^{9} \mathrm{~J}$. MiRET I SANS, Les cases de templers y hospitalers en Catalunya. Aplech de noves y documents històrichs, Barcelona, 1910; JOSEP Ma SANS TRAVÉ, Alguns aspectes de l'establiment dels Templers a Catalunya: Barberà, "Quaderns d'Història Tarraconense”, I (1977), pp. 9-58; la donació i ratificació a les pp. 30-32.
} 
1410 el Gran Priorat estava vacant i actuava com a lloctinent fra Guillem de Guimerà, comanador de Gardeny ${ }^{10}$. Per desgràcia no disposem de cap capbreu antic que ens indiqui què comprenia la comanda i quins eren els seus drets a començaments del segle XV; n'haurem doncs d'intentar la reconstrucció d'acord amb el que apareix al document i als capbreus posteriors ${ }^{11}$. La comanda tenia la senyoria sobre Barberà, Ollers, Pira i Montbrió; la senyoria de Barberà era compartida de fet amb el carlà, com a conseqüència d'una envitricollada història de drets i plets ${ }^{12}$, i també amb l'arquebisbe de Tarragona pel que fa al delme ${ }^{13}$.

Els ingressos per renda feudal eren: quístia a Barberà i Montbrió ${ }^{14}$, pernades a Ollers, censos o censals ${ }^{15}$, drets de forn a Barberà ("coqueleria"

${ }^{10}$ Fra Guillem de Guimerà fou comanador de Lleida de 1408 a 1432 (MIRET, Les cases, p 523); abans ell, o un homònim seu, ho havia estat de Barberà (1377-1379). A Barberà després de Guillem de Guimerà no consta cap comanador fins a Joan des Carrigues (segurament Garrigues) el 1429; Ibidem, p. 528. El Gran Prior Gracià de Maissèn morí el 1409; el seu successor for Gonçal de Funes (1412-1414); Ibidem, p. 520.

"En el capbreu 1591, quan Barberà era una de les quatre "cambres priorals" (comandes atribuïdes al Grap Prior de Catalunya), consten com a membres de la comanda Barberà, Pinatells (terme rònec), Pira, Ollers, Montbrió, Vallverd, Cogul, Biure i la quadra del Sant Redemptor, al terme dels Omells de na Gaia; però els nomenats a partir de Montbrió són segurament afegits posteriors al moment que estudiem (ACA, Ordres Militars, Sant Joan de Jerusalem, vol. 262). El primer capbreu en el qual consta la confessió del comú és de 1558; Ibidem, vol. 252. La quadra del Sant Redemptor té una història, que jo sàpigui desconeguda, que hauria interessat molt a la Regina i per això no em sé estar de resumir aquí: té l'origen en l'intent d'Alfons II, el 1188, de fundar un Orde Militar amb el mateix nom i d'obediència cistercenca, que havia de tenir la casa mare en un hospital amb la mateixa titulació, que s'havia de fundar a Terol. No devia passar de l'intent i aquesta quadra, d'altra banda tan llunyana de la seu de la fundació, passà, no sabem com, als Hospitalers (Ibidem, vol. 271).

${ }^{12}$ Ibidem, pp. 41-48. El carlà, a l'època Alfons sa Rovira, rebia una novena part de la major part dels ingressos feudals.

${ }^{13}$ Segons el capbreu de 1558 , el delme d'una partida del terme de Barberà corresponia a l'arquebisbe i en ella el comanador rebia una quarta part del delme recollit; en la resta del terme el delme era íntegre del comanador; ACA, Ordres Militars, Sant Joan de Jerusalem, vol. 252 (Capbreu de Barberà i Pira, 1558).

${ }^{14}$ Tenim notícia d'aquesta darrera pel capbreu de 1371; en els comptes, o no es va cobrar o anava englobada amb altres pagaments. ACA, Ordres Militars, Sant Joan de Jerusalem, vol. 250.

${ }^{15}$ Censal sembla indicar els censos d'origen feudal: el poble de Barberà paga un censal en ordi (en realitat en diners), que, a pesar del seu nom, té tota l'apariència d'un dret feudal; i el mateix es pot dir del censal de l'herba del castell. En canvi cens indicaria més aviat el pagament per cessions posteriors, però també antigues, mentre que les més modernes serien els anomenats terratges; però si cal considerar el cens renda feudal o renda de la terra fa de mal escatir. A efectes dels càlculs he considerat els censos $i$ censals com a renda feudal $i$ els terratges com a renda de la terra. 
i arrendament), lluïsmes, joves ${ }^{16}$, tragins ${ }^{17}$ a Barberà i Pira, delmes de blat $^{18}$ a Barberà, Ollers, Pira i Montbrió, delme de llana a Barberà i Ollers, delme de safrà a Barberà, Pira i Montbrió i delme de menuderies a Pira (pagat en diners) $)^{19}$. El conjunt dels ingressos feudals es pot veure al Quadre núm. I.

QUADRE I

INGRESSOS PER RENDA FEUDAL

\begin{tabular}{|c|c|c|c|c|c|c|c|}
\hline & sous & $\begin{array}{r}\text { blat } \\
\mathrm{hl}\end{array}$ & $\begin{array}{c}\text { ordi } \\
\mathrm{hl}\end{array}$ & $\begin{array}{c}\text { civada } \\
\mathrm{hl}\end{array}$ & $\begin{array}{c}\text { mestall } \\
\mathrm{hl}\end{array}$ & $\begin{array}{c}\text { Ilana } \\
\text { kg }\end{array}$ & $\begin{array}{r}\text { safrà } \\
\mathrm{kg}\end{array}$ \\
\hline quístia & 1061,00 & & & & & & \\
\hline pernades & 30,00 & & & & & & \\
\hline censal & 40,00 & 52,48 & & & & & \\
\hline cens & 168,22 & & 24,04 & 1,16 & & & \\
\hline lluïsmes & 260,17 & & & & & & \\
\hline "coqueleria" & 190,00 & & & & & & \\
\hline forn & 11,00 & & & & & & \\
\hline
\end{tabular}

${ }^{16}$ Les joves apareixen en el llibre de comptes perquè els que les fan dinen al castell; no sabem per tant ni quantes eren ni quin poble o pobles hi estaven obligats. Segons el capbreu de 1585, a Barberà el comanador disposava de les joves següents: qui tenia parell feia dos jornals al sembrar i qui tenia mula un jornal; dos dies més a l'entrar garbes, cada dia amb una mula, i dos dies més al batre. En aquests darrers casos no queda clar si es fa distinció entre els que tenen parell i els que només tenen mula. Totes les joves s'havien de fer en dies "de carn" i el senyor els havia de donar dinar i dos quartans d'ordi per cada jornal. Si els dinars pagats als jovers van ser ben comptabilitzats, al sembrar la comanda va disposar de 32 joves.

${ }^{17} \mathrm{Al}$ capbreu de 1585 no consta l'obligació de fer tragí, però sí que apareix (un dia) en el de 1764 (Ibidem, 271).

${ }^{18}$ Faig constar aquí els delmes comptabilitzats el 1410; a la nota següent figuren els delmes que consten als capbreus.

${ }^{19} \mathrm{~A}$ Barberà es pagava delme de tots els grans, de la verema, el safrà, el cànem i les "menuderies". Tot a la desena, pagant la primícia al rector $(1 / 30)$ i respectant la part de l'arquebisbe. El delme del safrà és com a tot arreu, més complicat: a la partida de l'arquebisbe paguen una unça de cada dotze; de l'unça de l'arquebisbe, el rector en retira la primícia i un com retirada aquesta el comanador rep $1 / 4$ de la resta; per tant l'arquebisbe obté un $4,16 \%$ de la collita, el rector un $2,77 \%$ i el comanador un $1,39 \%$. A la partida del comanador, es paga per superfície, de safrà vell 3 unces per quartó (1/4 de quartera) i de safrà nou 1,5 unces (al capbreu de 1558 resulta il-legible l'expressió "per quartó", que trec del capbreu de 1764 (Ibidem, 271), si bé les quantitats han variat: es paguen 4 i 2 unces respectivament; potser hi ha hagut per tant un canvi també en la unitat de superfície. Per la complexitat en el cobrament del delme del safrà, vegeu FELIU, El funcionament, p. 38. 


$\begin{array}{lrrrrrrrrr}\text { delme } & 48,92 & 60,12 & 9,85 & 46,32 & 23,10 & 7,61 & 4,32 & & \\ \text { joves (mínim) } & & \cdot & & & & & & 46 & \\ \text { TOTAL } & 1809,31 & 112.06 & 33,89 & 47,48 & 23,10 & 7,61 & 4,32 & 46 & \\ & & & & & & & & & \\ \text { valor censos i censals } & & 612,43 & 155,85 & 7,00 & & & & 775,28 \\ \text { valor delme } & & 701,58 & 63,86 & 280,28 & 149,76 & 12,00 & 266,85 & & 1474,33 \\ \text { VALOR TOTAL } & 1809,31 & 1314,01 & 219,71 & 287,29 & 149,76 & 12,00 & 266,80 & 4058,92\end{array}$

En diners el senyor recollia $1809,3 \mathrm{s.}^{20}$, procedents sobretot de la quístia de Barberà (1061 s. $)^{21}$, seguida dels lluïsmes $(260 \mathrm{~s}$.$) , la "coquele-$ ria" de Barberà (un dret sobre el forn, de 190 s.) i el cens de Barberà (165 s.) ${ }^{22}$. L'estimació de les rendes en espècie gairebé dobla aquest valor: comptant el blat a 13,5 s. per mitgera (preu mitjà del blat venut), l'ordi i el mestall a 7,5 s. (preu a què es valorà el censal de Barberà), la civada a 7 $\mathrm{s}^{23}$ i la llana i el safrà als seus respectius preus de venda, el resultat són 3341 s., procedents una tercera part dels censos i dues terceres parts dels delmes; i també en dues terceres parts del blat i la resta dels altres productes. Cal tenir en compte a més que no tenim dades del delme de la verema, que, pel capbreu de 1585, sabem que el comanador cobrava.

A més de la senyoria, la comanda disposava també de terres dominicals, tant en aquests termes com en altres de veïns (Sarral, Rocafort i Vallverd ${ }^{24}$ part dels quals havien estat cedits en diferents moments a cens, en grans o en diners, o a terratge; l'orde conservava però encara un extens honor gestionat directament ${ }^{25}$. El producte de les terres cedides diner.

${ }^{20}$ En tot el document utilitzaré per comoditat sous i decimals de sou o diners i decimals de

${ }^{21}$ Segons el capbreu de 1585 la quísita eren 90 ll. (1800 s.); la diferència deu correspondre a quantitats no cobrades.

${ }^{22} \mathrm{El}$ cens de Barberà eren 33 mitgeres d'ordi “a mesura de la pedra" i corresponien al dret de llòçol. El 1410 se'n pagaren $165 \mathrm{~s}$., que a $7,5 \mathrm{~s}$. mitgera serien 22 mitgeres; per tant la mitgera corrent era la meitat més grossa que la mesura de la pedra.

${ }^{23}$ Els comptes no proporcionen cap preu per la civada; normalment era una mica més barata que l'ordi.

${ }^{24} \mathrm{La}$ notícia sobre els drets en aquests pobles es troba en un document posterior, de 1471 , "Capbreu dels censos de tots los Membres de Barberà", ACA, Ordres Militars. Sant Joan de Jerusalem, armari 13, vol. 250.

${ }^{25}$ Per desgràcia aquests productes obtinguts per explotació directa i en gran part destinats al consum de la comunitat, són objecte d'un tractament comptable molt poc curós. Tampoc no coneixem l'extensió de l'hisenda senyorial el 1410. A l'hora de sembrar s'anomenen diverses partides: el tros sota el castell, les Obagues, devall les Forques, tros d'en Lois, hort del Masó, 
(terratge) no és gaire elevat (Quadre II); valorat als preus proposats anteriorment, dóna un total de 989 s., tres quartes parts del qual corresponen a blat i una quarta part a civada.

QUADRE II

RENDA DE LA TERRA (TERRATGE)

$\begin{array}{crc} & \text { blat (hl) } & \text { civada (hl) } \\ \text { Barberà } & 37,08 & 36,50 \\ \text { Puigvert } & 16,99 & \\ \text { Ollers } & 11,30 & 5,79 \\ \text { TOTAL } & 65,37 & 42,29 \\ & & \\ \text { VALOR (s.) } & 761,66 & 255,50 \\ \text { VALOR TOTAL (s.) } & 1017,16 & \end{array}$

A aquests ingressos s'hi ha d'afegir el producte de l'explotació directa de la hisenda del castell; però no sabem els ingressos que generà $\mathrm{i}$ per tant només hi podem fer una aproximació molt barroera. Dels dies treballats per llaurar i de la llavor gastada en podem obtenir una aproximació

\footnotetext{
les Pobles, davall de la vinya d'en Tarragó i a les parades damunt del Pont de Pedra. Per desgràcia no tenim res de semblant per a la vinya. El capbreu de 1585 enumera: un tros, part terra campa i part vinya tocant al castell, del qual no indica l'extensió; deu correspondre a la "vinya de la Closa", de 10 jornals, que figura al capbreu de 1591; l'hort del Masó, a la partida dels Diumenges, que el 1410 consta plantat de vinya, d'extensió $10 \mathrm{j}$. segons el capbreu de 1558 , però només 7 (o només 7 de vinya) en el capbreu de 1591. Un tros de terra campa $\mathrm{i}$ vinya a les Obagues, de $9 \mathrm{j}$. el 1558; el 1591 hi havia $3 \mathrm{j}$. de vinya. Una vinya al Pont de Pedra, estimada en $10 \mathrm{j}$, el 1558, però que no consta en el capbreu de 1591 , a no ser que es tracti de la vinya de la Font, de 5 o 6 jornals. Finalment la devesa, que devia ser bosquina el 1558 , ja que s'indica que proveïa de llenya la casa, però on el 1591 hí havia $506 \mathrm{j}$. de vinya. No podem saber si la reserva senyorial es va mantenir o va experimentar canvis, si bé m'inclino a creure que aquests devien ser poc importants en extensió (el 1591 apareix una "vinyeta" que no puc fer correspondre a cap finca anterior); si fos així, i tenint en compte que la relació de 1591 només parla de les vinyes, la reserva podia ser a Barberà d'uns $45 \mathrm{j}$. Els dies de llaurada i la quantitat sembrada porten a creure que era però bastant superior, si bé es podia tractar de terres als altres pobles de la comanda. Cal tenir en compte de no confondre els jornals de terra, mesura de superfície de 0,4928 ha (Alsina, Feliu, MARQUeT, Pesos, p. 165), amb el jornal com a pagament del treball diari.
} 
a la superfície sembrada ${ }^{26}$. La sembra del blat va ocupar 26 jornals i es van sembrar 20,18 hl; la civada va requerir 17 jornals sembrats amb 10,04 hl. Es va sembrar quatre dies més, sense que s'indiqui què.

Sobre quina superfície? No ho sabem, però podem intentar un càlcul aproximatiu de la superfície de la finca a través dels jornals esmerçats en llaurar i de la llavor sembrada. Ens serviran de guia, a falta de millor, els càlculs fets pel Vallès al $\mathrm{s}$. XIX i les estimacions de Francesc Valls pel segle $\mathrm{XVIII}^{27}$; no cal ni dir per tant que tot plegat és molt especulatiu. Al Vallès, per llaurar una ha es calcula que es necessiten 4 jornals (un jornal i mig per llaurar una quartera); això ens porta a 2 jornals per jornal de terra de Montblanc. La font no diu si la superfície es calculada llaurant amb bous o bé amb mules, però sembla molt poc espai per ser llaurat amb mules i a més el càlcul donaria una quantitat de llavor molt elevada, de manera que suposaré que es tracta de parells de bous. Valls indica que les mules llauraven una quarta part més que els bous, de manera que prenent com a base la xifra del Vallès, un parell de mules llauraria al dia 0,3125 ha i en 26 dies 8,125 ha. Acceptant la vella identitat quartera de sembra per quartera de terra, amb 17,19 hl es sembrarien 8,52 ha ${ }^{28}$. Els resultats són prou semblants per a ser verosímils. Amb els mateixos càlculs, les 17 jornals despesos per sembrar civada donarien una extensió de 5,31 ha, corresponents a $10,78 \mathrm{j}$.; en aquest cas el càlcul de la sembra resulta poc aprofitable: normalment la civada es sembra més espessa que el blat, però la relació llavor / dies llaurats indica una sembra més clara. Em sembla preferible per tant utilitzar les xifres que resulten de la llaurada. A la superfície dedicada

\footnotetext{
${ }^{26}$ Que doni les xifres amb decimals no obsta per a que es tracti d'estimacions amb un ample marge d'error; però com que sovint les utilitzo per recalcular quantitats, introduir xifres arrodonides encara ampliaria el marge d'error.

${ }^{27}$ Ramon Garrabou i Jordi Planas (eds.), Estudio Agrícola del Vallés (1874), Granollers, 1998. Francesc VALLS JUNYENT, La dinàmica del canvi agrari a la Catalunya interior. L'Anoia, 1720-1860. Montserrat, 1996. Jordi Planas i Francesc Valls m'assenyalaren els punts de les seves obres on es trobaven les dades qúe m'interessaven; a tots dos companys el meu agraïment.

${ }^{28} \mathrm{Cal}$ tenir present que aquesta identitat prové dels temps en què la quartera utilitzada a Barcelona pel blat no era la de 12 quartans, sinó la de 10 (57,93 l), de manera que una quartera per quartera, ambdues mesures de Barcelona, són 2,37 hl per jornal; per la quartera vella, vegeu Pere ORTí GOST, El forment a la Barcelona baixmedieval: preus, mesures i fiscalitat (1283-1345), "AEM", 22 (1992), p. 394. És també pràcticament idèntica a la sembradura que trobava al Pla d'Urgell al segle XVIII, d'una quartera i mitja de Lleida per jornal $(2,52 \mathrm{hl}$ per ha); Gaspar FELIU, El funcionament del règim senyorial a l'Edat Moderna. L'exemple del Pla d'Urgell. Lleida, 1990. Aventín, pel Vallès al s. XVI, accepta també la igualtat quartera de terra per quartera de sembradura; Mercè AVENTín I PUIG, La societat rural a Catalunya en temps feudals. Vallès oriental, segles XIII-XVI, Barcelona, 1996, pp. 164 i 169.
} 
al blat i a la civada cal afegir 1,25 ha, o sigui, $2,5 \mathrm{j}$. pels dies que no sabem què es va sembrar. La superfície sembrada seria doncs de 14,685 ha i per tant, tenint en compte que es sembrava any per altre, la superfície de terra campa de la reserva devia rondar les 29,37 ha, o sigui, els 59,60 j.

Per la vinya, els càlculs dels Vallès al segle XIX (però la productivitat d'un home amb una aixada no ha progressat gaire) són de 3 jornals per quartera de Granollers, o sigui 8,17 jornals per ha; per tant la cavada diària seria de $1224 \mathrm{~m}^{2} 29$; els 100 jornals de cavar vinya pagats pel castell, donarien una extensió de 12,24 ha, o sigui 24,8 jornals de Montblanc. En el capbreu de 1558 en surten 20 jornals ( 8,7 ha) en dues peces, més parts en dues peces més; en el de 1591 eren més de 30 j. (13 ha). Això no permet inferir l'extensió de la vinya el 1410 , però la descripció de les peces que es fa en aquest capbreu permet pensar que no podia haver canviat gaire. Els 25 j. semblen doncs un supòsit raonable. Per tant l'heretat del castell pot ser estimada entorn a les 29,37 ha de sembradura i 12,25 de vinya; en total 41,62 ha (uns 84,45 jornals).

Segons el full solt, ja citat, insertat dins del llibre de comptes, fra Guillem Sancho, successor de fra Bernat de Vilaregut, rebé d'aquest 391,14 hl de blat ${ }^{30}$. Per desgràcia no sabem quan blat trobà fra Bernat al castell, ni tampoc el que podia procedir de drets que fra Bernat no comptabilitzà. Les entrades que coneixem són 177,43 hl (delmes, censals i terratges) ${ }^{31}$; les sortides, 30,03 hl venuts, 45,57 portats al molí per la despesa de la casa, 0,97 repartits en diverses almoines, 19,11 lliurats com a salaris (als saigs i als advocats) i 20,17 sembrats: en total $115,85 \mathrm{hl}$. La collita de la reserva més el blat que hi pogués haver anteriorment al castell sumaven 329,56

\footnotetext{
${ }^{29}$ VALLS, La dinàmica, p. 166, dóna una producció molt baixa, 0,1 j. d'Igualada, de 0,4896 ha, o sigui, $489 \mathrm{~m}^{2}$ (un quadrat de $22 \mathrm{~m}$ i escaig), que potser corresponguin al primer i fatigós treball d'arrabassar un erm. La fangada de Lleida era de $871,61 \mathrm{~m}^{-}$i fangar és una feina més lenta que cavar; Alsina, Feliu, Marquet, Pesos, p. 154.

30337 mitgeres i 7 punyeres. Fra Guillem es carrega també 334 mitgeres i 3 punyeres de forment procedent de Comalats, 3 mitgeres i una faneca de blat lliurat pel batlle de Segura, 30 mitgeres i mig punyeró de mestall de Comalats i de Biure i 27 mitgeres i una faneca de civada lliurada per fra Bernat i el batlle de Biure i 2 faneques d'ordi procedent de porgar 4 mitgeres de mestall. He prescindit d'aquestes quantitats: les úniques que podien procedir de la comanda de Barberà estricta era la part de mestall Iliurada per Vilaregut, sumada amb la del batlle de Biure, i l'ordi procedent de la porga del mestall. La resta procedia de Comalats o altres llocs. Per facilitar la comprensió utilitzaré principalment la transformació de les quantitats en hl.

${ }^{31} 46,57$ de censal, 60,13 de delme i 65,37 de terratges.
} 
$\mathrm{hl}^{32}$, que no podien procedir totes de l'explotació directa (resultaria una ratio collita de 19,58), però que tampoc no ens permeten quantificar-ne la collita $^{33}$. La resta d'entrades de l'heretat es reduïen a l'hort i a les nous: el corral sembla inexistent, donat que per algunes festes es compren gallines.

Les despeses segures van ser 194,70 s. gastats en la compra de productes o el pagament de serveis, $901,35 \mathrm{~s}$. pagats per jornals o treballs i $640,17 \mathrm{~s}$. despesos en menjar ${ }^{34}$ : total $1736,22 \mathrm{~s}^{35}$. El detall de les despeses es pot veure més endavant en els Quadres III, V i VI. El cost dels jornals va ser sens dubte superior, donat que desconeixem el cost de la sega $^{36}$.

\section{L'ANY AGRÍCOLA}

Els comptes de fra Bernat permeten veure la successió de feines de l'any agrícola en una explotació que podem considerar típica de gran part de Catalunya: secà amb conreu de cereals i vinya ${ }^{37}$. D'altra banda la seqüència no difereix massa de la que podríem trobar fins al nostre segle (fins a la motorització del camp) ni segurament en els segles anteriors al document.

\footnotetext{
${ }^{32} \mathrm{El}$ blat restant més el blat tret menys els ingressos per renda feudal o renda de la terra.

${ }^{33}$ Un any per altre $\mathrm{i}$ acceptant els rendiments mitjans que troba Duran a Vallmoll al segle XVI $(4,45$ per 1), la reserva podia donar uns $90 \mathrm{hl}$; Montserrat DURAN I PUJOL, Producció $i$ renda agrària a la Catalunya del segle XVI. En: Núria SALES (et al.), Terra, treball i propietat. Classes agràries i règim senyorial als Països Catalans. Barcelona, 1986, p. 197.

${ }^{34}$ Una part de la despesa de menjar es deguda a que molts treballadors es queden a dinar al castell. Això no té cap efecte però sobre el salari: se'ls doni o no dinar (o en alguns casos berenar), el sou és el mateix. L'excepció serien els dinars pagats com a conseqüència de joves o tragins: el dinar era l'única contraprestació per aquest treball obligatori.

${ }^{35}$ Es tracta de la quantitat pagada per fra Bernat. La despesa d'alimentació hauria de compendre també com a mínim el pa i el vi. Intentaré una aproximació al cost d'aquests aliments més endavant.

${ }^{36}$ Més endavant intento una estimació d'aquest cost.

${ }^{37} \mathrm{La}$ "trilogia mediterrànea", d'arrel grega o com a mínim romana, és un fals historiogràfic aplicat a l'edat mitjana: l'olivera era molt marginal, fins $i$ tot en el sentit de consistir en alguns olivers en els marges dels camps. Fins a finals del segle XVII no sembla que es pugui parlar de plantades d'olivera. Bonnassie dedicà unes magnífiques pàgines als greixos comestibles altmedievals, recalcant la poca presència de l'oli d'oliva; Pierre BONNASSIE, La Catalogne du milieu du X' à la fin du XI' siècle. Croissance et mutations d'une société, 2 vol., Tolouse, 1975, vol. I, p. 95-96. Un altre argument en el mateix sentit és que la menció del delme de l'oli és molt més escassa que la del vi, així com les lluites al s. XVIII per la seva imposició; FelIU, El funcionament, p. 3).
} 
Començant a Sant Joan, tal com fa el llibre de comptes, la primera feina, que ocupa del 20 de juliol a l'11 d'agost és batre; es llogà gent 9 dies, però consten altres dies de batre, no sabem si només amb les joves i el moço del castell: com a mínim els tres dies en què sabem la quantitat batuda, no fou llogat ningú ${ }^{38}$. Els tres dies coneguts, l'erada va rendir el 15 de juliol 32,25 mitgeres de blat; el 10 d'agost 18 mitgeres, també de blat, i el 13 d'agost unes 45 mitgeres entre ordi, civada i espelta ${ }^{39}$. Podríem pensar que el segon dia l'era no era plena. Amb una mitjana de 38 mitgeres per dia, en 9 dies s'haurien pogut obtenir 342 mitgeres $(396,25 \mathrm{hl})$.

Un cop acabat el batre, la segona quinzena d'agost es dediquen alguns dies a cavar l'hort, netejar la cèquia i tallar llenya; i també hi ha alguns jornals per rentar els vaixells del celler. Del 5 a l'11 de setembre es devia entrar gra, ja que sabem que es va llogar una persona per guardar la porta. La resta del mes les activitats principals semblen haver estat tallar llenya i collir i batre les nous.

A primers d'octubre es treballà molts dies en posar a punt el celler $i$ uns pocs en birbar el lli i treure el cànem de la bassa. A partir del dia 12 començà la verema i del dia 14 la sembra; aquesta es perllongà de moment fins al dia 17 , mentre que la verema durà fins al dia 25 . A cavall entre octubre es dedicaren alguns dies a espadar el cànem, a collir les ravanícies i cavar l'hort, per a reemprendre la sembra cinc dies més. Després, fins a final d'any, només es llogà gent per tallar o entrar llenya, activitat que es perllongà fins al 10 de gener. Entremig però, es dedicaren alguns dies a cavar l'hort i a plantar els alls.

El 14 de gener es començaren a esporgar les vinyes, on treballaren de 3 a 5 homes fins al dia 29. Pel febrer hi hagué bastants jornals d'entrar i mesurar blat i civada $i$ eixermentar la vinya ${ }^{40}$, així com esporgar el raïm grec i les parres. Pel març gairebé no hi hagué activitat agrària, al menys que es reflectís en el pagament de jornals. Només els darrers dies del mes es començà a cavar la vinya, feina que ocupà 4 o 5 homes, amb molta intensitat fins a final d'abril i més escadusserament fins al 9 de maig.

\footnotetext{
${ }^{38}$ Dotze dies sembla per tant un mínim; el màxim serien quinze dies: els citats i tres més en què es llogà gent per a entrar gra o palla.

${ }^{39} \mathrm{~L}$ 'erada neta fou de 31 mitgeres i dues faneques, un cop treta la primícia del rector, que per una altra anotació sembla que era un catorzè, i el delme de l'arquebisbe, segurament un onzè: 31,5 mitgeres netes havien de provenir de 44,76 mitgeres brutes.

${ }^{40}$ Es tracta de recollir els serments esporgats i fer-ne feixos.
} 
Mentrestant s'havia començat a birbar el cereal, a partir del 24 d'abril, primer amb una dona i després amb dues o tres, fins al final del període comptabilitzat. També a la primera quinzena de maig hi ha alguns jornals per rentar vaixells i trescolar el vi.

Com ja ha quedat dit, l'acabament sobtat dels comptes ens impedeix veure la importància que sens dubte tenia la sega, fet que ens impossibilita per a treure gaires conclusions dels comptes.

\section{ELS JORNALS I ALTRES DESPESES DE TREBALL}

L'activitat de l'explotació es duia a terme mitjançant uns pocs treballadors fixos (un mosso ${ }^{41}$, una dona a la cuina, un escolà que segurament devia ajudar en altres feines) i jornalers llogats per dies per a feines concretes. El cost total (fixos i jornalers) fou com a mínim de $928,68 \mathrm{s.}^{42}$; els fixos costaren $97,33 \mathrm{~s}$, , als que caldria afegir uns $275 \mathrm{~s}$. del salari del mosso $^{43}$. Els salaris fixes coneguts són $72 \mathrm{~s}$. per vuit mesos de salari de la dona de la cuina ${ }^{44}, 7,33 \mathrm{~s}$. per tres parells de sabates de la dona, $19 \mathrm{~s}$. per quatre parells de sabates i drap burell pel vestuari de l'escolà i $18 \mathrm{~s}$. pel salari de 24 dies del nou mosso. Els jornals pagats foren 410 , dels quals 317,5 foren d'home i 92,5 de dona. Els jornals d'home costaren 744,77 s., amb una mitjana de $2,315 \mathrm{~s}$. per jornal. Els jornals de dona costaren 96,31 s. i la mitjana fou d'1,04 s. A més els homes es quedaren 101 vegades a dinar al castell i 49 a berenar (al temps de la poda) i les dones 27 vegades. Caldria afegir-hi l'estimació feta del cost de la sega: 383,5 s. per 59 jornals. La repartició d'aquests jornals entre les diferents feines es pot veure al Quadre III:

\footnotetext{
${ }^{4 !}$ Pel desembre es lloga fins a Nadal un mosso, no sabem si a més a més o bé en lloc de l'anterior (que podia estar malalt o absent per alguna raó); m'inclino per aquesta segona responsabilitat, ja que el desembre no sembla un moment de feina que justifiqués el lloguer d'un segon mosso. No sabem quan cobrava el mosso, però el substitut cobrà $18 \mathrm{~s}$. per 24 dies, o sigui, a 8 d. diaris: per tant el mosso devia cobrar 270, potser 300 sous a l'any.

${ }^{42}$ Caldria afegir-hi com a mínim el salari del mosso i els dels segadors, que portarien la suma a uns $1200 \mathrm{~s}$.

${ }^{43}$ Els salaris anuals s'acostumaven a fixar en florins. El mosso llogat pel desembre cobrà a 9 d. dia; per 365 dies són 273,75 s. a l'any: 275 s. són 25 florins.

${ }^{44} \mathrm{El}$ salari anual era de 10 florins l'any, o sigui, 110 sous, i tres parells de sabates, però només estigué de Sant Joan a finals de febrer.
} 


\section{QUADRE III}

DESPESES SALARIALS

$\begin{array}{ccr}\text { HOME } & \text { DONA } & \text { TOT A L PREU FET } \\ \text { jornals sous jornals sous jornals sous }\end{array}$

CAMP

CEREAL

batre

enmagatzemar

mesurar

sembrar

birbar

transport

SUBTOTAL

FIBRES

cànem

Ili

SUBTOTAL

HORT

cavar

plantar

collir

escurar la

cèquia

nous

SUBTOTAL

TOTAL CAMP

VINYA

\section{veremar}

portar verema

esporgar

eixarmentar

cavar

SUBTOTAL

CELLER

portar aigua
$11 \quad 10,83$

$4 \quad 5,16$

5

$\begin{array}{ll}8 & 10,83\end{array}$
$15 \quad 14,83$

$10 \quad 9,66$

$14 \quad 14,82$

$\begin{array}{lll}32 & 37,16 \quad 32 & 37,16\end{array}$

$26 \quad 31,82$

4650.82

$72 \quad 82.64$

$\begin{array}{llll}5 & 4,83 & 5 & 4,83\end{array}$

$\begin{array}{llll}2 & 1,66 & 2 & 1,66\end{array}$

$\begin{array}{llll}7 & 6.49 & 7 & 6.49\end{array}$

$\begin{array}{rrrr}10 & 13,08 & 10 & 13,08 \\ 2 & 2,66 & 2 & 2,66 \\ 2 & 2,83 & 2 & 2,83\end{array}$

33

$2 \quad 2,33$

$4 \quad 3,33$

$3 \quad 3$

$19 \quad 23,9$

4555,72

$4 \quad 3.33$

27.23

5760,64

102116,36

20,58 


rentar vaixells
trescolar
SUBTOTAL
TOTAL VINYA
TOTAL CONREUS
ALTRES DESPESES
LLENYA
tallar
portar
SUBTOTAL
OBRES
paleta
manobre
SUBTOTAL
DIVERSOS
guardar porta
altres
SUBTOTAL
ASSALARIATS (sous, roba i sabates)
dona cuina
escolà
missatge
SUBTOTAL
TOTAL ALTRES DESPESES

TOTAL JORNALS

TOTAL DESPESES SALARIALS
GASPAR FELIU

\begin{tabular}{|c|c|c|c|c|}
\hline $\begin{array}{ll}4 & 10,5\end{array}$ & & 4 & 10,5 & \\
\hline 23 & & 2 & 3 & 3 \\
\hline $28 \quad 21,83$ & & 28 & 21,83 & \\
\hline $195,5 \quad 473,75$ & $35,5 \quad 35,67$ & 231 & 509,42 & \\
\hline $240,5 \quad 529,47$ & $92,596,31$ & 333 & 625,78 & \\
\hline
\end{tabular}

$\begin{array}{rrrr}22 & 33,5 & 22 & 33,5 \\ 21 & 26,91 & 21 & 26,91 \\ 43 & 60,41 & 43 & 60,41\end{array}$

$10 \quad 29$

$10 \quad 29$

$14 \quad 21,67$

\begin{tabular}{ll}
$14 \quad 21,67$ \\
\hline
\end{tabular}

2450,67

$24 \quad 50,67$

$8 \quad 2,66$

82,66

$2 \quad 5.25$

25,25

$10 \quad 7.91$

$10 \quad 7.91$

$77 \mathbf{1 1 8 , 9 9}$

7118,99

$317,5648,46$

$92,596,31$

410744,77

67,58

$\begin{array}{rrrrrr} & & 79,33 & & 79,33 & \\ & & & & & 19 \\ 24 & 18 & & 24 & 18 & \\ 24 & 18 & 72 & 24 & 97,33 & 19\end{array}$

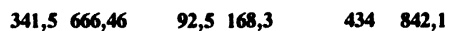

86,58

la majoria dels jornals se'ls endugué la vinya i l'obtenció del vi i també foren els més cars en mitjana, fora dels jornals del mestre paleta. El cereal requerí un terç dels jornals de la vinya, amb un cost que no arribà a la 
sisena part: el jornal mitjà ve a ser per tant la meitat ${ }^{45}$. La provisió de llenya costà tres quartes partes dels jornals pagats per la terra campa i les obres una mica menys.

La resta de despeses salarials es feren en pagaments a preu fet (treballs al celler o transports); foren 9 pagaments a vuit persones diferents, amb un total de $89,42 \mathrm{~s}$.

Els salaris masculins eren superiors als femenins, com es pot veure al Quadre IV, tot i que la comparació es veu dificultada perquè les tasques no acostumen a ser les mateixes. Però per la mateixa feina, acostumen a cobrar el mateix, com és el cas dels homes i dones llogats per ajudar a batre o entrar blat, que guanyen tots $1 \mathrm{~s}$. diari. Només al veremar veiem que l'únic home llogat cobra $1 \mathrm{~s} .6 \mathrm{~d}$. mentre que les dones cobren $1 \mathrm{~s}$., menys una que guanya $1 \mathrm{~s} .2 \mathrm{~d}$. Com a mínim podem dir que no sempre els salaris femenins eren inferiors.

\begin{tabular}{llcl} 
& \multicolumn{3}{c}{ QUADRE IV } \\
& & SALARI MITJÀ \\
& HOME & DONA & TOTAL \\
CEREALS & 1,22 & 1,10 & 1,15 \\
FIBRES & & 0,93 & 0,93 \\
HORT & 1,26 & 0,83 & 1,18 \\
VINYA & 2,68 & 1,00 & 2,40 \\
LLENYA & 1,41 & & 1,41 \\
OBRES & & & \\
$\quad$ paletes & 2,90 & & 2,90 \\
$\quad$ manobres & 1,90 & & 1,90
\end{tabular}

Al llarg de l'any els salaris evolucionaren de la manera següent: al juliol i l'agost, pel batre, el jornal era d'un sou per homes i dones, amb poques excepcions a $10 \mathrm{~d}$. Al setembre tallar llenya, feina més pesada, es paga normalment a 1,25 s. o a 1,5 s., encara que es troben altres jornals; -en canvi portar la llenya amb el mul sempre es paga a 1,5 s. Batre les nous, feina d'home es paga a 1,17 s.; en canvi les dones que les colliren només reberen $10 \mathrm{~d}$., igual que per birbar el lli, o treure el cànem de la bassa.

\footnotetext{
${ }^{45} \mathrm{Cal}$ tenir en compte que es disposava de joves al llaurar, a l'entrar garbes i al batre i que desconeixem quan costà el segar. Si s'hagués pagar o comptabilitzat tot això és possible que la despesa del cereal fos semblant a la de la vinya.
} 
Treballar a l'hort es paga habitualment a 1,33 s., però també hi ha jornals a $1,17 \mathrm{~s}$., $1,25 \mathrm{~s}$. i $1,5 \mathrm{~s}$. i fins i tot un a $2 \mathrm{~s}$, , que possiblement correspongui a més d'un dia.

A la verema, com ja he dit, l'home que porta el mul guanya 1,5 s. i les dones que veremen $1 \mathrm{~s}$., fora de "na Elena", que cobra $1,17 \mathrm{~s}$.; però quan es tracta d'espadar el cànem guanya $1 \mathrm{~s}$., com les altres dones. Pel mateix temps, l'home que sembra guanya $1,33 \mathrm{~s}$. excepte dos dies a 1,5 s. A la vinya els esporgadors guanyaven $1,83 \mathrm{~s}$. fins al 16 de gener i $2 \mathrm{~s}$. en endavant. Per cavar la vinya els homes començaren al març guanyant $3 \mathrm{~s}$, que pujaren a $3,17 \mathrm{~s}$. a partir del 15 d'abril; a partir de finals d'abril i per tot maig es continuen pagat jornals a 3,17s., però la majoria es paguen a 3,5 s.; el jornal sembla dependre del dia, no del treballador ${ }^{46}$. Les dones guanyen $1 \mathrm{~s}$. per eixermentar i $1,17 \mathrm{~s}$. per birbar.

Els especialistes guanyaven una mica més: Jaume de Contijoch, per podar el grec i les parres, cobrà $2,33 \mathrm{~s}$. per dia. També netejar els vaixells del celler sembla una feina especialitzada i ben pagada: Andreu de Riu cobrà jornals de 3,5 s. per rentar els vaixells i també en Daudé, encara que altres dies aquest només cobrà $1,75 \mathrm{~s}$.; la major part d'aquesta feina la féu però Guillem Avala a preu fet, ja que cobrà de cop $44 \mathrm{~s}$. Els paletes van cobrar a raó de $3 \mathrm{~s}$. el mestre Guillem Llor, però només 2,5 s. Miquel de Riu, també paleta; els manobres cobraren tots a raó d'un sou i mig: la feina d'especialista estava millor pagada que la de pagès, encara que en les feines més dures els pagesos podien guanyar el mateix jornal que un artesà.

I fins i tot més en el moment de la sega. Al Vallès es calcula que es necessita un jornal i mig per segar una quartera ${ }^{47}$, o sigui, 4 jornals per ha, en les terres de rendiment més baix, amb un salari que més que dobla el jornal de cavàr. La mitjana d'aquest fou de 3,28 s., de manera que 6,5 s. sembla un salari de segador raonable. Segar les 14,685 ha sembrades costaria segons aquest càlcul, $383,5 \mathrm{s.}^{48}$

\footnotetext{
${ }^{46} \mathrm{La}$ majoria dels cavadors va passar pels diversos jornals; només dos homes, Pere de Riu i Macià Sanaüja, cobren sempre a $3 \mathrm{~s}$. $6 \mathrm{~d}$., molt possiblement perquè només es van llogar en els darrers dies, que és quan es pagava aquest jornal.

${ }^{47} \mathrm{En}$ aquest cas es tracta de la quartera de vinya, de $3672,38 \mathrm{~m}^{2}$.

${ }^{48} \mathrm{He}$ intentat trobar el cost de la sega per un altre camí, que en principi semblava oferir més garanties, ja que era de la mateixa època i comarca: utilitzar la comparació els costos de birbar i segar de la granja de Riudabella. Però els anys pels quals és possible la comparació donen resultats molt diferents: el 1443, segar costà 6,7 vegades més que birbar, el 1446, només 1,6 vegades més. És cert però que el primer d'aquests anys només s'hi posaren 72 jornals, mentre
} 
Què representen aquests jornals? El mateix fra Bernat de Vilaregut l'any 1416 portà uns comptes del castell de Vallfogona, publicats per Miret $^{49}$. Per ell i el seu macip, que semblen ser els únics habitants del castell, gastà el primer dia 3 diners de pa, 2 de vi i 4 entre oli i peix: $4 \mathrm{~d}$. i mig per persona, en un dia una mica especial. Si ho rebaixem a $4 \mathrm{~d}$. tindríem que un jornal mitjà d'home $(2, \mathrm{~s}$.) permetria alimentar 7 persones (presicindint de totes les altres despeses) i un jornal de dona (1 s.), 2 persones i mitja. El problema no era tant la migradesa del jornal, com la seva escassedat. Ja hem vist que durant mesos sencers el castell no llogava ningú o molt poca gent, com tampoc no ho feia evidentment els dies de festa; i l'estacionalitat de les feines agrícoles porta a creure que els altres propietaris tenien un comportament semblant.

Ser jornaler devia ser molt dur, tant que és molt possible que fossin molt pocs els jornalers purs: el que abundaven era més aviat els pagesos amb poca terra.

En un moment o un altre treballaren al castell com a mínim 53 homes diferents i 13 dones, pertanyents a de 35 cases $^{50}$. Alguns treballadors o famílies són cridats més assiduament. Destaca Bernat Lucona, que a la vegada era el saig del senyor ${ }^{51}$, que va obtenir 26 jornals treballant en cavar, tallar i entrar llenya, treballar a l'hort i fins i tot fent de manobre. També la seva dona i el seu fill van fer un jornal cadascun; en total la família Lucona va aconseguir 28 jornals que li proporcionaren 49 , 33 s. i 20 dinars al castell. Més jornals féu encara Pere de Riu, que arribà a 30 i obtingué 65,83 s.; apart d'un parell jornals de manobre, treballầ sobretot a la vinya, esporgant, cavant i treient la verema. No sabem quina relació tenia amb Andreu, Miquel i Ramon de Riu, que entre tots treballaren 6 dies pel castell. Arnau Fillol féu 18 jornals, tots a la vinya, sobretot esporgant i cavant, i cobrà $47,5 \mathrm{~s}$. La família Santpere treballà 20 dies, però només cobrà 13,83 s.; la raó és que la major part d'aquests jornals els va fer el fill,

que el segon foren 232 (potser es feren tres passades?). El 1445 segar i batre costà 2,9 vegades més que els 98 jornals de birbar; el 1447, 7,3 vegades més; el 1448, només 2,33; ALTISENT, Les granges, pp. 29-31. Sembla que és millor no utilitzar unes dades tan disperses.

${ }^{49}$ MiRET, Les cases, pp. 564-565.

${ }^{50} \mathrm{He}$ comptat els noms individuals, però sense doblar en cas que només aparegui de vegades el cognom, tot $\mathrm{i}$ que es podia tractar de dues persones diferents; en el compte de les famílies he agrupat tota la gent amb el mateix cognom i això també és molt possiblement excessiu.

${ }^{51}$ Com a tal cobrà una mitgera de blat. 
llogat per guardar la porta a un sou irrisori: 4 d. per dia i el menjar. Si resultessin formar part d'una mateixa família, els Pellicer serien dels que més haurien treballat pel castell: $28 \mathrm{j}$. i mig entre Bartomeu (6 j.), Guillem (12 j.) i Pere i el seu fill (10,5 j.), amb una remuneració conjunta de 71,07 s. ${ }^{52}$. Un altre possible grup familiar són els Sanaüja: hi ha 4 jornals a nom "d'en Sanaüja”, 4 a nom de Macià Sanaüja i 7 més a nom de Miquel Sanaüja; en total cobraren $38,17 \mathrm{~s}$. Altres treballadors cridats sovint foren Berenguer d'Aragó (15 jornals i 27,66 s.), Guillem d'Arnet, la dona del qual era la cuinera del castell (14 jornals, i 35,17 s.) i Antoni Besant (13 jornals i 26,25 s.). Segurament però tingueren més importància Guillem Avala, que cobrà 67,83 s., en gran part per preparar les bótes del celler, i Jaume Contijoch, que no va fer més que 8 jornals per 22 sous, però que sembla l'especialista en el raïm grec i les parres.

Dues dones destaquen entre les treballadores habituals del castell: na Dardanca, amb 23 jornals i na Sabatera amb 22,5. La primera s'endugué 24,67 s. i la segona 24,33 ; totes dues van treballar a l'era i birbant i eixarmant la vinya.Les altres dones surten molt menys: la filla d'en Foguet féu 10 jornals, na Portera 8 , etc.

\section{LES DESPESES D'EXPLOTACIÓ}

A més dels jornals pagats, l'explotació comportava també altres despeses en materials, estris de treball, reparacions, ferrar els animals i fins i tot la compra de mig paller; en conjunt no eren massa importants (Quadre V). Les despeses de manteniment de la casa no les podem considerar despeses d'eplotació, a excepció de la despesa en el menjar, a la que dedicaré l'apartat següent. Deixant de banda aquesta només és important la despesa en il·luminació $i$ en estris de cuina: les candeles de sèu ${ }^{53}$ són l'apartat més important de les compres i en conjunt es despengué més en il-luminació que en eines o en despeses dels animals. La suma total d'aquestes despeses és però moderada: poc menys de 200 sous. S'hi podrien afegir $270 \mathrm{~s}$. pagats a dos frares i un beneficiat en concepte de vestuari.

\footnotetext{
${ }^{52}$ Pere Pellicer i el seu fill obtingueren $30,58 \mathrm{~s}$.

${ }^{53}$ Les candeles de cera i els ciris semblen dedicats a la capella.
} 


\section{QUADRE V}

\section{DESPESES CASA}

IL·LUMINACIÓ

candeles seu
candeles cera
altres

34,75

10,08

13,42

ESTRIS DE CUINA

\section{olles}

1,67

escudelles $\quad 2,41$

càntir $\quad 1,17$

vidre $\quad 1,17$

altres $\quad 1,83$

MATERIALS

claus de pany $\quad 3,33$

claus $\quad 1,08$

paper i tinta $\quad 5,5$

corda pel pou 7

llàntia capella $\quad 0,83$

TOTAL DESPESES DE CASA

84,24

DESPESES EXPLOTACIÓ

EINES

rella (reparar)

garbells i sedassos

13,5

altres

4,42

DESPESES ANIMALS

ferrar

albardes $\mathrm{i}$ sàrries

paller (mig)

claus

anelles menjadores

12,67

DESPESES CELLER

aixetes $\mathrm{i}$ cèrcols

escombres

argadells

17,74

8,25

altres

54,04 


$\begin{array}{lr}\text { DESPESES HORT } & 10,33 \\ \text { TOTAL DESPESES DE L'EXPLOTACIÓ } & 110,46 \\ \text { TOTAL } & \mathbf{1 9 4 , 7}\end{array}$

Aquestes despeses ens permeten un coneixement dels preus. Evidentment aquests tenen tots els inconvenients: sovint es tracta d'una sola compra, no coneixem qualitats, són preus locals i només per un any... però davant l'escassedat de dades per aquestes èpoques he pensat que valia la pena recollir-los a l'Apèndix II.

\section{LA DESPESA DE CUINA I EL MENJAR}

La despesa en menjar representava una tercera part de la despesa total, tot i que no hi figuren ni el pa ni el vi, que n'eren de ben segur els components principals, ni els productes de l'hort. Tampoc no hi comptabilitzem el sou de "la dona de la cuina" ${ }^{54}$, que figura en l'apartat dedicat als salaris, ni els estris de cuina.

Vilaregut divideix la despesa de menjar en ordinària (la despesa diària) i extraordinària (les compres fetes de tant en tant $i$ fins $i$ tot un sol cop a l'any). El resum d'ambdues es pot veure al Quadre VI. El producte principal és la carn, que és el companatge més corrent ${ }^{55}$. La carn comprada dia a dia representava el $41,66 \%$ de la despesa; si hi afegim la carn de porc, destinada a salar (un $15,23 \%$ ) resulta que la carn s'enduu un $56,89 \%$ del diner gastat. Segueixen el vi $(13,39 \%)$, l'oli $(8,17 \%)$, el peix, fresc i salat $(7,24 \%)$ i els ous $(7,09 \%)$; de la resta de productes només la sal s'atança al $2 \%$.

Aquests percentatges són però enganyosos: el pa i el vi no hi consten, ni tampoc els productes de l'hort. Ens hi podem atançar? Només d'una forma molt especulativa. Pel pa, podem partir de les quantitats portades al molí, 45,57 hl; si li apliquem la moltura típica (un setzè)

\footnotetext{
${ }^{54}$ Encara que es parla sempre de "la dona de la cuina", sembla que era la única minyona del castell.

${ }^{55} \mathrm{Com}$ a curiositat, les joves, que comportaven el dret dels jovers al dinar, s'havien de fer "en dia de carn"; ACA, Ordes Militars, Sant Joan de Jerusalem, vol. 252 (capbreu de 1558).
} 
quedarien $42,72 \mathrm{hl}$, que a $70 \mathrm{~kg}$ per hl donarien $2990,53 \mathrm{~kg}$ de $\mathrm{pa}^{56}$; com que el forner cobrava la puja (un pa de cada vint), en podem detreure un $5 \%$ i ens queden $2841 \mathrm{~kg}$. El nombre de racions calculades (afegint-hi la part proporcional al mes i escaig pel qual falten els comptes) és de 2849 , cosa que dona una ració d'un $\mathrm{kg}$ de pa per persona ${ }^{57}$; com que tant la moltura com la fabricació del pa es pagaven en espècies, el cost de la ració es pot obtenir dividint el preu del blat pel nombre de racions: els $45,57 \mathrm{hl}$ a 13,5 s. la mitgera valen $530,96 \mathrm{~s}$, , quantitat que dividida pel nombre de racions dóna un cost per ració de $2,24 \mathrm{~d}^{58}$.

Pel vi anem més a les fosques. Es van comprar 12,75 sesters en dues vegades $^{59}$, amb un cost total de $83 \mathrm{~s}$. No sembla que n'hi hagués prou: si el sester era, com he suposat, un terç de carga, serien 656,031 , que donarien una ració per comensal de 0,23 l per dia, amb un cost de 0,35 d. Sempre que trobem despeses de vi són més altes: els pobres de la Pia Almoina gastaven en vi una mica més de la meitat del que gastaven en blat; els rics, tant o més ${ }^{60}$. Proposo acceptar la proporció de la despesa que feren fra Bernat i el seu macip al castell de Vallfogona: $2 \mathrm{~s}$. de vi per $3 \mathrm{~s}$. de $\mathrm{pa}^{61}$; això donaria $1,49 \mathrm{~d}$., que al preu a què fou comprat el vi serien 1,02

\footnotetext{
${ }^{56} \mathrm{El}$ pes del hl de blat l'he calculat en $70 \mathrm{~kg}$. $70 \mathrm{~kg}$ pel hl resulta una mica baix avui (la norma va de 72 a $75 \mathrm{~kg}$ ), però els blats medievals no eren normalment tan plens. Tot i que s'acostuma a dir que una quartera de Barcelona pesa $55 \mathrm{~kg}(79 \mathrm{~kg}$ per hl), a Florència al s. XVI el millor blat "cima delle cime" es considerava de $75 \mathrm{~kg}$ per hl blat; per tant el blat corrent medieval segurament era més lleuger. En un càlcul aproximat com aquest, es pot considerar que el pes del blat $\mathrm{i}$ el del pa són iguals: $100 \mathrm{~kg}$ de blat en poden donar 85 de farina per a fer pa corrent (amb segon); i de $100 \mathrm{~kg}$ de farina en surten 120 de pa: de $100 \mathrm{~kg}$ de blat en podrien sortir 102 de pa, per tant no val la pena de fer tantes operacions.

${ }^{57}$ Encara que avui pugui semblar el contrari, no era una ració exagerada pels costums alimenticis de l'època $\mathrm{i}$ fins $\mathrm{i}$ tot de temps no tan allunyats. Al segle XVIII s'acostuma a calcular la quantitat anual de blat necessària en 8 quarteres per persona: treient-ne el setzè pel molí $i$ el vintè pel forner, resulten 950 grams per dia.

${ }^{58} \mathrm{El}$ cost pot ser una mica elevat pel fet que considerem que es tractava de pa de blat; però no sembla que hi hagués més d'una taula i costa de pensar que els frares s'acontentessin amb un pa inferior.

${ }^{59} \mathrm{El} 6$ d'agost es van comprar 6 sesters i dues quartes a 8 s. sester, i el 18 d'octubre 6 sesters i mig, a $5,5 \mathrm{~s}$. sester. Com que la primera compra costà $50 \mathrm{~s}$., i 6 sesters en valien 48 , una quarta havia de valdre un sou i per tant havia de ser un vuitè de sester.

${ }^{60}$ Pels pobres, María ECHÁNIZ, La alimentación de los pobres asistidos por la Pia Almoina de la Catedral de Barcelona según el libro de cuentas de 1283-1284. En: RiERA (et al.), Alimentació, p. 191. Pels rics, Rafael CONDE y DELGADO DE MOLINA, Fonts per a l'estudi del consum alimentari en els temps medievals: fonts de l'Arxiu de la Corona d'Aragó. En: Antoni RIERA I MELIS (et al.), Alimentació i societat a la Catalunya medieval. Barcelona, 1988, pp. $39,41,43-44$ i 48.

${ }^{61}$ MiRET, Les cases, p.
} 
1 per persona i dia; una quantitat generosa, però no en excès, per l'època; d'altra banda significaria una quantitat molt petita respecte a la collita: aproximadament un $20 \%$.

Per l'hort (i les nous) podem considerar com a despesa el cost de producció: 30,9 s. El percentatge que representava cada aliment, tenint en compte els costos estimats del pa, del vi i de l'hort, es pot veure a la tercera columna del Quadre VI.

QUADRE VI

DESPESA DE MENJAR

DESPESA ORDINÀRIA

$\begin{array}{lccc} & \text { sous } & \% & \% \text { amb pa i vi } \\ \text { carn } & 266,67 & 41,66 & 17,14 \\ \text { ous } & 45,42 & 7,09 & 2,92 \\ \text { peix } & 37,75 & 5,90 & 2,43 \\ \text { peix salat } & 3,75 & 0,59 & 0,24 \\ \text { SUBTOTAL } & 353,58 & 55,23 & 22,72\end{array}$

\section{DESPESA EXTRAORDINÀRIA}

$\begin{array}{lccc} & \text { sous } & \% & \% \text { amb pa } \\ \text { oli } & 52,33 & 8,17 & 3,36 \\ \text { vi } & 85,75 & 13,39 & 5,51 \\ \text { sal } & 12,58 & 1,97 & 0,81 \\ \text { pebre } & 6,25 & 0,98 & 0,40 \\ \text { porc } & 97,50 & 15,23 & 6,27 \\ \text { gallines } & 7,00 & 1,09 & 0,45 \\ \text { pesca salada } & 4,83 & 0,75 & 0,31 \\ \text { formatge } & 5,00 & 0,78 & 0,32 \\ \text { cebes } & 1,50 & 0,23 & 0,10 \\ \text { fesols } & 1,92 & 0,30 & 0,12 \\ \text { cigrons } & 1,83 & 0,29 & 0,12 \\ \text { arròs } & 0,92 & 0,14 & 0,06 \\ \text { mel } & 5,33 & 0,83 & 0,34 \\ \text { neules } & 1,35 & 0,21 & 0,09 \\ \text { pimenta } & 2,50 & 0,39 & 0,16 \\ \text { SUBTOTAL } & 286,59 & 44,77 & 18,42 \\ \text { TOTAL } & \mathbf{6 4 0 , 1 7} & 100,00 & 41,14 \\ \text { pa (estimat) } & 530,96 & & 34,12 \\ \text { vi (estimat) } & 353,97 & & 22,75\end{array}$


De pa se'n menjava sempre i de carn sempre que es podia; això vol dir cada dia menys els dies d'abstinència: divendres i dissabtes, tota la quaresma i uns pocs dies més repartits al llarg de l'any. Només tenim una indicació del preu de la carn: el dia 6 de gener se'n compraren 6 lliures, que costaren 5, 5 sous, a $11 \mathrm{~d}$. la lliura. El preu segurament no era estable al llarg de l'any, però a efectes de càlcul li hem de considerar. Aquell dia amb 6 lliures menjaren 23 persones. La lliura de Barberà feia 346 gr $^{62}$, de manera que la racció mitjana de carn fou de $90 \mathrm{gr}$; era potser un extraordinari? Segurament no: pocs dies més tard, la carn per 8 persones costà 22 diners; al mateix preu serien 2 lliures, amb una racció de 86 gr; això sense comptar que a la nit es devia consumir carn de porc, bàsicament cansalada.

La distribució i el cost del companatge es pot veure al Quadre VII; quan no es podia menjar carn, el susbtitut primer eren els ous, que només falten durant els mesos de febrer i març (quan les gallines es "despullen", o sigui, deixen de pondre) ${ }^{63}$; secundàriament es menjava peix fresc mentre que el peix salat és realment el darrer recurs i només apareix als mesos de desembre a abril ${ }^{64}$. No puc aportar cap dada de quantitat o de preu pels ous. Pel peix fresc, com per la carn, també una sola menció de quantitat i preu: pel maig 2 lliures de peix costaren $10 \mathrm{~d}$. i en menjaren 7 persones; sortiren a gairebé 100 gr per persona.

El cost de la ració mitjana per persona la podem obtenir dividint la despesa ordinària pel nombre de menjades fetes, que ens dóna 1,67 d. i sumant-li el cost del pa, de l'hort i de la despesa extraodinària, però dividits per l'estimació de comensals fins a Sant Joan (2849). En aquestes condicions, el pa costaria $2,23 \mathrm{~d}$., el vi $1,49 \mathrm{~d}$. l'hort $0,13 \mathrm{~d}$. i la resta de la despesa extraordinària $0,85 \mathrm{~d}$. tot plegat, $4,70 \mathrm{~d}$.; sembla una mica elevat, però de fet, no es devia menjar pas malament, al castell! El Quadre VII mostra aquestes dades i l'evolució del nombre de menjars i del cost per mesos.

\footnotetext{
${ }^{62}$ Considero la lliura normal; si es tractés de lliures carnisseres (36 unces en lloc de 12), la racció alimentícia resultaria molt elevada: 270 grams de carn.

${ }^{63}$ Els ous de pasqua simbolitzen segurament els primers ous de l'any.

${ }^{64} \mathrm{La}$ quaresma comença amb uns dies que es menja peix salat; és l'únic moment en que podem saber una mica com es menjava: es compren fesols, cigrons o arròs per acompanyar el peix salat.
} 
QUADRE VII

DESPESA EN COMPANATGE PER MESOS

$\begin{array}{llcllc}\text { mesos } & \begin{array}{l}\text { carn } \\ \text { diners }\end{array} & \begin{array}{l}\text { sous } \\ \text { diners }\end{array} & \begin{array}{l}\text { peix } \\ \text { diners }\end{array} & \begin{array}{l}\text { peix salat } \\ \text { diners }\end{array} & \begin{array}{l}\text { TOTAL } \\ \text { sous } \\ \text { juny (24-30) }\end{array} \\ 27 & 16 & & & 12,31 \\ \text { juliol } & 353 & 88 & & & 103,64 \\ \text { agost } & 317 & 77 & 10 & & 104,47 \\ \text { setembre } & 382 & 36 & 35 & & 111,04 \\ \text { octubre } & 497 & 97 & & & 146,93 \\ \text { novembre } & 394 & 78 & 15 & & 127,83 \\ \text { desembre } & 245 & 78 & 36 & 10 & 113,06 \\ \text { gener } & 384 & 51 & 55 & 4 & 114,89 \\ \text { febrer } & 269 & & 36 & & 69,19 \\ \text { narç } & & & 158 & 20 & 57,00 \\ \text { abril } & 202 & 24 & 89 & 11 & 89,99 \\ \text { maig (1-18) } & 130 & & 19 & & 42,08 \\ \text { TOTAL } & 3.200 & 545 & 453 & 45 & 1091,43\end{array}$

El llibre no permet conéixer gran cosa dels costums alimenticis de l'època. Se'n pot treure en prou feines que per Nadal es compraren gallines i dolços (neules, mel, pimenta) i a la quaresma, com ja he dit, alguns dies es compren fesols o cigrons o bé arròs per acompanyar el peix salat ${ }^{65}$. És molt possible que la resta de l'any l'alimentació consistís, a dinar, en una olla de verdures (només es citen els alls, les cebes i les ravanícies, però l'hort en podia oferir d'altres) amb carn, peix o bé ous; a la nit, possiblement sopes de pa i potser una mica de cansalada o carn de porc.

\section{UNA APROXIMACIÓ AL COMPTE D’EXPLOTACIÓ}

Tant pel que fa a despeses com pel que fa a ingressos, els comptes de Vilaregut són massa incomplets per a intentar una aproximació als resultats de l'explotació. Però aporten també prou dades per a incitar a

\footnotetext{
${ }^{65}$ Algunes indicacions més es poden obtenir dels comptes que el mateix fra Bernat de Vilaregut portà el 1416 pel castell de Vallfogona: peix salat i espinacs, peix salat $\mathrm{i}$ fesols, peix salat i llenties, peix i guixes, ous $\mathrm{i}$ faves, ous i cigrons. Com es pot veure, els dies que es menja carn no cita mai cap acompanyament. Sembla ben bé que es tracti d'una dieta de carn, pa i vi; MIRET, Les cases, pp. 564-568.
} 
l'atreviment; és cert que no es tracta de res més que d'un conjunt d'especulacions, però em sembla que tot i l'ample marge d'error inherent, poden ajudar a comprendre millor el funcionament i la lògica d'una explotació senyorial com Barberà. Per distingir bé les dades certes de les suposades, d'ara endavant escriuré en cursiva aquestes darreres.

Les dades i estimacions utilitzables figuren al Quadre VIII. D'altra banda, encara que l'explotació donés un resultat nul o fins i tot una mica deficitari, cal tenir present que permetia mantenir durant l'any la família (frares i criats), necessària per a la supervisió i el cobrament dels drets senyorials. En aquest supòsit caldria sumar als ingressos de l'explotació la quantitat que hauria estat necessari despendre per a assegurar la realització de les joves i el cobrament dels drets senyorials.

Pel que fa al cereal, amb una ratio collita-llavor del 4,45 per 1 pel blat $^{66}$ la collita neta (descomptada la llavor per l'any següent) serien 60,16 hl, que a $13,5 \mathrm{~s}$. mitgera valdrien $698,92 \mathrm{~s}$. No valoro la resta de cereals, que sembla que servien per alimentar els animals de l'explotació. Les despeses certes pugen a $97,77 \mathrm{~s}$. la sega l'he estimada en $383,5 \mathrm{~s}$. per tant els costos de producció dels cereals serien de $481,27 \mathrm{~s}$. El balanç seria lleugerament positiu encara que pràcticament s'igualaria si s'haguessin hagut de pagar les joves: $184 \mathrm{~s}^{67}$.

Respecte a la vinya, si a les 12,24 ha en què l'he estimada els apliquem el rendiment de 4,5 cargues per jornal ${ }^{68}$, la collita teòrica seria de 140,25 hl. Al preu mitjà del vi comprat per l'ús del castell $(6,73 \mathrm{~s}$. per sester $^{69}$, la collita valdria $1834,31 \mathrm{~s}$. Les despeses sumen $583.01 \mathrm{~s}$., de manera que la vinya sembla un bon negoci.

\footnotetext{
${ }^{66}$ És la proporció d'una explotació a Vallmoll per alguns anys del s. XVI; Montserrat DURAN I PUJOL, Producció i renda agrària a la Catalunya del segle XVI. En: Núria SALES (et al.), Terra, treball $i$ propietat. Classes agràries $i$ règim senyorial als Països Catalans. Barcelona, 1986, p. 197. Poso en cursiva les xifres deduïdes.

${ }^{67} \mathrm{~L}$ 'única vegada que consta que es lloga un home amb un mul, precisament per a segar, cobra $4 \mathrm{~s}$.

${ }^{68}$ És l'estimació que es fa al cadastre del Palau d'Anglesola (Feliu, El funcionament, p. 118) i queda entre el màxim i el mínim assenyalats per Eva Serra per Belianes al segle XVI (Eva SERRA I PUIG, Consideracions entorn de la producció $i$ la productivitat agràries de la Catalunya del segle xvii, "Estudis d'Història Agrària", I (1978), p. 136). La carga de vi feia al Palau d'Anglesola 110,975 1.; el rendiment seria de 11,39 hl per ha.

${ }^{69} \mathrm{Pel}$ contingut del sester i la seva discussió vegeu l'Apèndix I.
} 
La resta de despeses fan però que l'explotació directa tanqui amb dèficit, si bé cal tenir en compte que d'aquestes despeses en vivien tot l'any fra Bernat $i$ els altres dos frares que composaven la comunitat.

\section{QUADRE VIII}

\section{COMPTE D'EXPLOTACIÓ}

INGRESSOS
estimació blat

estimació hor

TOTAL EXPLOTACIÓ

Dèricit

renda feudal

renda terra

blat enmagatzennat o sous

698.92

DESPESES

blat

jornals cereal

menjar

sega

verema

jornals

menjar

30.90

despeses gen.

\section{Compres}

mosso (24 dies)

mosso

estable

transports

treballs diverso

casa

llenya

obres

compres

jornals

menjar

2564.13

$-754.77$

4058.92

1017.16

vestuari frares
salaris

almoines sous

90,50

559.92

23.09

110,46

18.00

270.00

2,66

31,67

8.75

60.41

50,67

84.24

98,33

151-

9.44

331 -

8.90

270,00

222,66

8.39 


\begin{tabular}{|c|c|}
\hline d'altres procedències" & 3751.04 \\
\hline blat Comalats & 4512.38 \\
\hline delme verema & \\
\hline TOTAL & 15903.63 \\
\hline SUPERȦVIT & 12083.68 \\
\hline
\end{tabular}

D'altra banda el dèficit quedava més que compensat pels ingressos de la renda feudal, de la renda de la terra i d'altres que no podem comptabilitzar. Tot i això, sense el blat de Comalats la renda de Barberà no arribaria a les 400 lliures; i amb Comalats, seria d'unes 600, a les que s'hauria d'afegir el delme de la verema; sense ser una quantitat despreciable, no permetia viure massa com un senyor.

El dèficit estimat no arriba a les 40 ll.; donat l'ample marge d'error en què ens movem, ni tant solament podem assegurar que l'explotació fos deficitària, si bé tampoc no sembla gaire rendible. En tot cas, mentre Poblet anà abandonant l'explotació directa de les seves granges cap a mitjans del $\mathrm{s}$. $\mathrm{XV}^{71}$, l'honor senyorial de Barberà continuà figurant als capbreus fins al segle XVIII, si bé aviat el seu conreu devia ser deixat en mans dels arrendadors de la senyoria, que més aviat el devien sotsarrendar que no pas explotar-lo directament.

\footnotetext{
${ }^{70} \mathrm{D}$ 'aquesta quantitat $\mathrm{s}$ 'ha restat el blat suposadament collit, que en cas contrari seria comptabilitzat dues vegades.

${ }^{71}$ ALTISENT, Les granges, pp. 116-118.
} 


\begin{abstract}
APÈNDIX I
Les mesures normalment utilitzades al document deuen ser les de Barberà, que no s'anomenen mai; això vol dir que són les mesures per defecte. En canvi es fa sovint menció de les mesures de Montblanc.

De fet, pels grans, les mesures de Barberà i de Montblanc són les mateixes: mitgera de 115,864 1, dividida en 2 quarteres, 4 faneques i 16 quartans ${ }^{72}$; Barberà hi afegeix una mitgera censal de 112,243 1., que no sembla que hagi estat utilitzada als comtes de fra Bernat.

Els comptes de 1410 estan portats en mitgeres, quarteres, faneques i punyerons; la sal es compra a quartans i a punyerons. Encara que hi ha una menció discordant, la relació de preus indica que un quartà devien ser tres quartes parts de punyeró; per tant la mitgera contindria 12 punyerons. També compten en somades, equivalents a una mitgera i mitja o tres quarteres $(173,796 \mathrm{l})$. Al capbreu de $1558^{73}$ es fa constar que la vila fa cada any al senyor un cens per lloçol de 33 mitgeres d'ordi, "mesura de la pedra"; fra Bernat comptabilitza 22 mitgeres per aquest concepte; per tant la "mesura de la pedra", que devia ser la mesura antiga de Barberà, feia 77,242 1 .

Apareixen també en els comptes les mesures de Tarragona, amb una equivalència de 6 mitgeres de Barberà per 8 quarteres i 4 punyerons de Tarragona. Segons la reducció de 1585, les mesures de Tarragona eren quartera de 72,335 I dividida en 12 quartans; però ambdues equivalències resulten incompatibles: les 6 mitgeres de Barberà serien 695,184 l, que fins i tot dividint per 9 (donat que no sabem l'equivalent del punyeró de Tarragona) donaria una quartera de 77,24 1. A la inversa, si pensem que la quartera de Tarragona és correcta i que el punyeró era igual al quartà, la mitgera de Barberà només hauria de fer 98,483 l. Per desgràcia en aquest cas fra Bernat dóna el preu de venda, però no la quantitat resultant, que permetria una millor comprobació.
\end{abstract}

\footnotetext{
${ }^{72}$ Alzina, Feliu, Marquet, Pesos, pp. 262 i 328. La única diferència és que a Barberà es diu que la faneca és igual a la quartera, però es tracta segurament d'un error de transcripció; els comptes de fra Bernat separen l'una de l'altra.

${ }^{73}$ ACA, Ordes Militars, Sant Joan de Jerusalem, v. 252.
} 
Pira, que el 1585 confessa utilitzar les mesures de Montblanc, en tenia de pròpies el 1410: 18 mitgeres i 1 punyeró de Pira eren 16 mitgeres 3 punyerons de Montblanc, després de pagar el redelme al batlle. Per les menuderies de Pira es pagaren $70 \mathrm{~s}$., que quedaren reduïts a $48 \mathrm{~s} .11 \mathrm{~d}$. un cop pagats el quart a l'arquebisbe i el redelme al batlle: una reducció del $30 \%$. Com que la part de l'arquebisbe era un quart, el redelme era un vintè. Per tant les 16 mitgeres i 13 punyerons $(16,8125)$ de Montblanc procedien de 15,972 mitgeres de Pira. Per tant la mitgera de Pira seria de 109,724 1 .

Apareix també una mitgera de Pallerols amb la qual es paga el cens d'Ollers. 21 mitgeres de Pallerols es transformen en 16 mitgeres i una fanega de Montblanc, pagat redelme al batlle. Si la taxa del redelme era la mateixa, 19,95 mitgeres de Pallerols equivalien a les citades de Montblanc i per tant la mitgera de Pallerols equivalia a 94,375 1; en un altre pagament, 2 mitgeres de Pallerols, es transformen, pagat el redelme, en 1 mitgera, 1 quartera i 2 punyerons: la mitgera resultant seria de 99,09 1; el 1585 la mitgera de Pallerols dóna 91,967 l i la d'Ollers 90,7601 .

El censal de Montbrió de 26 mitgeres, 10 punyerons i un quart de punyeró, es feu equivaldre a 24 mitgeres de Montblanc: si pensem que, encara que no consti a la partida, també se'n pagà el redelme al batlle, la mitgera de Montbrió seria de 109,873 1, pràcticament igual a la de Pira.

Més difícil resulta escatir les mesures del vi: l'única mesura citada és el sester. Per desgràcia el sester com a mesura pel vi no arribà al segle XVI més que al Pallars i per la qual no puc donar una capacitat segura. La meva proposta és que es tracta d'un subdivisor de la carga oblidat o canviat de nom, segons els llocs. A Pallars trobem repetidament sesters de 4 mitgeres (Isona, Pobla de Segur, Sort,...); a les Muntanyes de Prades, cargues de 3 poals de 4 mitgeres $^{74}$. Es pot pensar doncs que poal i sester eren en aquest cas sinònims, tots dos equivalien a 4 mitgeres i per tant que el sester és un terç de la carga. Aplicant aquesta igualtat a la carga de Montblanc, el sester resultant seria de 51,461.

L'oli es compra a quartans i a lliures, que suposem que són les mesures declarades per Barberà en la reducció de 1585: quartà de 8,04 1, dividit en 311 . de 2,681 .

Apareix també la lliura de pes; he suposat que es tracta de la lliura de Montblanc (que era la utilitzada a Barberà), de 346 grams.

\footnotetext{
${ }^{74}$ Alsina, Feliu, Marquet, Pesos, pp. 314, 349, 386, y 74 (també 397) respectivament.
} 


\section{APÈNDIX II}

\section{ALGUNS PREUS AL COMENÇAMENT DEL SEGLE XV}

Tot i que es tracta de preus locals, sovint amb una sola menció o, pitjor encara, amb poques mencions, però molt dispars, la informació sobre preus en aquesta època és tan escassa que crec que val la pena recollir-los; per a major facilitat, indico el preu en mesures de l'època $i$ en mesures modernes i de forma tabulada.

\begin{tabular}{|c|c|c|c|c|c|c|}
\hline & $\begin{array}{l}\text { preu } \\
\text { màxim }\end{array}$ & preu mínim & unitat & $\begin{array}{l}\text { preu } \\
\text { màxinı }\end{array}$ & $\begin{array}{l}\text { preu } \\
\text { mínim }\end{array}$ & $\begin{array}{l}\text { me- } \\
\text { sura } \\
\text { mo- } \\
\text { derna }\end{array}$ \\
\hline blat & 14,17 & 11,25 & mitgera & 12,23 & 9,71 & $\mathrm{hl}$ \\
\hline vi & 8,00 & 5,50 & sester & 14,80 & 10,17 & $\mathrm{hl}$ \\
\hline oli & 6,33 & 3,51 & quartà & 78.72 & 43,65 & hl \\
\hline $\begin{array}{l}\text { carn de } \\
\text { moltó }\end{array}$ & 0,92 & & lliura & 2,65 & & $\mathrm{~kg}$ \\
\hline $\begin{array}{l}\text { carn de } \\
\text { porc }\end{array}$ & 0,58 & & lliura & 1,68 & & $\mathrm{~kg}$ \\
\hline gallina & 1,75 & & parells & 1,75 & & unitat \\
\hline peix fresc & 0,42 & & lliura & 1,20 & & $\mathrm{~kg}$ \\
\hline congre & 1,67 & & Iliura & 4,83 & & $\mathrm{~kg}$ \\
\hline arengades & 0,03 & & unitat & 0,03 & & unitat \\
\hline $\begin{array}{l}\text { sardines } \\
\text { rovellades }\end{array}$ & 0,02 & & unitat & 0.02 & & unitat \\
\hline formatge & 0,67 & 0,50 & Iliura & 1,93 & & $\mathrm{~kg}$ \\
\hline sal & 1,17 & 0,75 & quartà ${ }^{75}$ & 16,09 & 10,36 & hl \\
\hline pebre & 7,00 & 5.00 & lliura & 20.24 & 14,46 & $\mathrm{~kg}$ \\
\hline fesols & 0,17 & & lliura & 0,49 & & $\mathrm{~kg}$ \\
\hline fesols & 1.75 & & quartà & 21,76 & & $\mathrm{hl}$ \\
\hline cigrons & 1,83 & & quartà & 22,76 & & hl \\
\hline cebes & 0,50 & & forcs & & & \\
\hline mel & 11,88 & 5,00 & Iliura $^{76}$ & 34,35 & 14,46 & kg \\
\hline
\end{tabular}

${ }^{75}$ La sal es compra a quartans i a punyerons. Suposo que es tracta de la mesura del blat.

${ }^{76} \mathrm{La}$ gran diferència en el preu de la mel s'estableix entre les compres a roves i les compres a lliures. 


$\begin{array}{lcccc}\text { neules } & 0,02 & \text { unitat } & 0,02 & \text { unitat } \\ \text { pimenta } & 0,83 & \text { unça } & 28.80 & \mathrm{~kg}\end{array}$

\section{RÉSUMÉ}

L'étude d'un mince livre de comptes de la commanderie de Barberà, appartenant à l'Ordre Militaire de l'Hôpital de Jérusalem permet de connaître un peu plus sur le revenu seigneurial, le cours des travails de l'année agricole, les habitudes alimentaires et diverses genres de prices et salaires. Quoique la reconstruction des donnée exige beaucoup de déductions, on semble que l'exploitation directe par les seigneurs n'était pas très rentable s'il l'était en tout cas; mais elle aidait au maintien du revenu féodal et du revenu de la terre, ce qu'était bien plus important.

\section{SUMMARY}

The survey of a thin accountancy book of the feudal estate of Barberà, belonging to the Military Order of Hospital of Jerusalem, allows us to know a little more about the lord's net income, the course of annual fieldwork, the feeding habits and notes for several kinds of prices and wages. Even though the reconstruction of the reckoning needs a lot of inferences, it seems clear that the direct farming by landlords was not very profitable if it was profitable at all: but it helped to the maintenance of the most important feudal and land income. 